\title{
Occurrence and management of atrial arrhythmia after long-term Fontan circulation
}

\author{
Joachim Weipert, $M D^{\mathrm{a}}$ \\ Christian Noebauer, MD ${ }^{\mathrm{a}}$ \\ Christian Schreiber, MD \\ Martin Kostolny, MD ${ }^{\mathrm{a}}$ \\ Bernhard Zrenner, MD ${ }^{\mathrm{b}}$ \\ Annett Wacker, MD ${ }^{\mathrm{C}}$ \\ John Hess, MDc \\ Ruediger Lange, $\mathrm{MD}^{\mathrm{a}}$
}

From the Departments of Cardiac Surgery,
Cardiology, ${ }^{\text {a }}$ and Pediatric Cardiology and
Congenital Heart Disease, ${ }^{\mathrm{c}}$ German Heart
Center Munich, Technical University Mu-
nich, Munich, Germany.

Read at the Eighty-third Annual Meeting of The American Association for Thoracic Surgery, Boston, Mass, May 4-7, 2003.

Received for publication May 2, 2003; revisions requested July 31, 2003; accepted for publication Aug 11, 2003.

Address for reprints: Joachim Weipert, MD, Department of Cardiac Surgery, German Heart Center Munich, Lazarettstr. 36, 80636 Munich, Germany (E-mail: Weipert@dhm.mhn.de).

J Thorac Cardiovasc Surg 2004;127:457-64 $0022-5223 / \$ 30.00$

Copyright $(9) 2004$ by The American Association for Thoracic Surgery

doi:10.1016/j.jtcvs.2003.08.054
Objectives: In patients after the Fontan operation, we determined risk factors for late failure and for intra-atrial re-entrant tachycardia at 15 to 20 years' follow-up. Midterm results after electrophysiologic ablation therapy for these tachycardias were also evaluated.

Methods: Current follow-up was available in 162 patients (2005 patient-years) with a wide range of underlying diagnoses operated on between February 1978 and May 1995. Risk factor analysis included patient-related and procedure-related variables, with late failure and the incidence of re-entrant tachycardia as outcome parameters.

Results: Forty late failures were observed (2.0 per 100 patient-years). At 15 years, Kaplan-Meier estimated survival was significantly $(P=.007)$ better for patients with tricuspid atresia (93\%) compared with that for patients with complex congenital malformation $(71 \%)$. The sole multivariable risk factor for Fontan failure was the type of underlying diagnosis. At 20 years' follow-up, overall freedom from tachycardia was estimated to be $46 \% \pm 12 \%$. Acute success of electrophysiologic ablation was seen in $25(83 \%)$ of 30 patients, and Kaplan-Meier estimated freedom from recurrent tachycardia was $81 \% \pm 10 \%$ at 3 years. Multivariate analysis identified duration of Fontan circulation as the sole risk factor for re-entrant tachycardias.

Conclusion: After the modified Fontan operation, long-term survival in patients with tricuspid atresia was significantly better compared with that in patients with complex congenital malformations. As first-choice therapy for atrial re-entrant tachycardias, we recommend electrophysiologic ablation therapy.

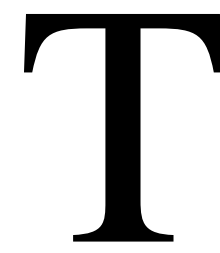

he development of intra-atrial re-entrant tachycardia (IART) exposes patients after long-term Fontan circulation to serious morbidity. ${ }^{1-4}$ Depending of the Fontan population and the time of follow-up, Kaplan-Meier estimates of freedom from tachycardias vary in a wide range from $12.5 \%$ to $80 \% .^{1,2,5-8}$ Antiarrhythmic drug therapy, antitachycardia pacing, or both offer limited arrhythmia control. A few small series report the use of electrophysiologic mapping and radiofrequency ablation techniques with good acute success rates but high early recurrence rates of arrhythmia. ${ }^{9,10}$ Therefore in patients with tachycardia undergoing the Fontan operation, conversion to a total cavopulmonary connection combined with a modified Cox maze procedure has been advocated. ${ }^{11-13}$ Recent data from patients with a total cavopulmonary connection showed that we can expect significantly fewer patients with tachycardia after this technique as opposed to patients after the classical Fontan operation and its modification. ${ }^{14}$ 
The purpose of this article is to document our results with radiofrequency ablation therapy of tachycardia in patients after the Fontan operation. We determined patientand procedure-related risk factors influencing late Fontan failure, development of IARTs, and management strategy.

\section{Methods}

\section{Patient Population}

Patients undergoing modifications of the Fontan procedure at the German Heart Centre Munich operated on between February 1978 and May 1995 were studied. The indication for the modified Fontan operation was given when a significant increase of cyanosis, reduction of physical capabilities, or both was observed. In each patient preinterventional and postinterventional data were extracted by means of review of the medical records or personal contact. Preoperative cardiac catheterization data were available for all patients and, in conjunction with echocardiographic data, served as the basis for assessment of atrial and ventricular morphology and hemodynamic data. The actual clinical condition was verified in the outpatient pediatric cardiology department. To facilitate data analysis on the basis of the morphology of the underlying congenital heart disease, we assigned the patients either to a tricuspid atresia ( $\operatorname{TrA}$ ) group or to a complex congenital malformation (CCM) group, who were not amenable for 2-ventricle repair. Patients with a hypoplastic left heart syndrome were not referred for surgical therapy at that time. Also, patients were assigned to the type of Fontan pathway: either right atrial to right ventricle (RA-RV) or right atrial to pulmonary artery (RA-PA) types of Fontan procedures. During that time, the RA-PA connection was either a direct RA-PA anastomosis, or the connection was performed with allografts or with a lateral tunnel of autologous atrial tissue. Prosthetic material, as used in recent modifications for total cavopulmonary connections, was not used.

\section{Electrophysiologic Technique}

If patients had been treated unsuccessfully with an average of 3 antiarrhythmic drugs, an ablation procedure was indicated. Antiarrhythmic drugs were discontinued more than 5 plasma half-lives before the study. For the procedure, patients were sedated with midazolam (1-2 mg administered intravenously). A 64-electrode basket catheter (Constellation; EP Technologies, San Jose, Calif), providing 56 bipolar electrocardiograms, was placed in the right atrium through an $11 \mathrm{~F}$-long sheath inserted from the femoral or internal jugular veins. On the basis of echocardiographic estimation of right atrial dimensions, basket diameters between 48 and 90 mm were used. ${ }^{15,16}$ After basket catheter deployment, a $5 \mathrm{~F}$ decapolar catheter with an interelectrode distance of 2 to $10 \mathrm{~mm}$ spacing between electrodes was positioned in the coronary sinus (in cases when the coronary sinus was not surgically drained in the left atrium) to detect small changes in intracardiac position. The third catheter was used as a roving catheter to record and pace from selected sites in the right atrium and to perform radiofrequency ablation.

\section{Definitions}

Fontan survivors were defined as patients with an intact Fontan pathway of any modification. Fontan failure was defined as death at the time of last follow-up because during late follow-up, no takedown of the Fontan circulation to a systemic to pulmonary shunt procedure was performed. Time to IART was defined as the period beginning 30 days after the Fontan procedure and extending to the date of the first electrophysiologic investigation. By defining time to IART in this way, the uncertain effects of early arrhythmias in patients without frequent follow-up were eliminated. Patients with antiarrhythmic drugs and regular sinus rhythm were censored at the time of the most recent follow-up.

\section{Statistical Analysis}

Overall late Fontan failure and the incidence of postoperative IARTs served as outcome parameters. The influence of early mortality was eliminated by defining survival time as the period beginning 30 days after the Fontan procedure. Patients in whom the Fontan circulation did not fail were censored at the time of last follow-up. Estimated actuarial survival and freedom from IARTs were determined by using the Kaplan-Meier method. Significance during univariable analysis was assessed by using the log-rank test when the type of diagnosis for Fontan survival and the type of Fontan anastomosis for IART were the outcome parameters during the Kaplan-Meier procedure. For multivariable analysis, the Cox proportional-hazards regression model was used to establish the variables independently predictive of Fontan failure and the incidence of IARTs. Hazard ratios with $95 \%$ confidence intervals were constructed for the significant multivariable predictors. Final models were derived by using the forward stepwise selection procedure. Variables having $P$ value of less than .1 in the univariable analyses were entered as candidates into the Cox regression models. A $P$ value of less than .05 was required for the variable to be retained in the equation. All reported $P$ values are 2 tailed. Statistical analysis was performed with the SPSS software package (version 10.1; SPSS, Inc, Chicago, Ill). Data are presented as means \pm SEM or SD as indicated.

\section{Results}

\section{Patient Characteristics}

A total of 182 modified Fontan procedures have been performed during the study period, and 162 long-term survivors (2005 patient-years) were included in the study. Eighty-four patients were male, and 78 were female. In 92 patients the diagnosis of $\operatorname{TrA}$ was the leading cardiac malformation. Seventy patients with a wide range of underlying cardiac malformations were summarized as having CCMs. Forty-five patients had no palliative procedures before the Fontan operation. One hundred seventeen patients had previously undergone a total of 160 palliative procedures: 63 patients had at least one systemic to pulmonary artery shunt, 43 patients had pulmonary artery banding, 5 patients had coarctation repair, 1 patient had a bidirectional Glenn procedure, and 5 patients had comissurotomy of the pulmonary valve. Age at first palliation was not significantly $(P=.255)$ different for patients with TrA and CCMs, being $2.4 \pm 3.5$ years (median, 0.75 years) and $1.8 \pm 2.4$ years (median, 0.8 years), respectively. From the total of 162 patients, 40 late Fontan failures occurred (1.99 per 100 patient-years). 
TABLE 1. Preoperative cardiac catheterization data (mean \pm SD) in patients undergoing the modified Fontan operation

\begin{tabular}{lccc}
\hline Late Fontan failure & $\begin{array}{c}\text { No } \\
(\mathbf{n}=\mathbf{1 2 2})\end{array}$ & $\begin{array}{c}\text { Yes } \\
(\mathbf{n}=\mathbf{4 0})\end{array}$ & $\begin{array}{c}\boldsymbol{P} \\
\text { value }\end{array}$ \\
\hline $\begin{array}{l}\text { Right atrial pressure } \\
(\mathrm{mm} \mathrm{Hg})\end{array}$ & $6.0 \pm 3.0$ & $6.0 \pm 2.4$ & .88 \\
$\begin{array}{l}\text { Left atrial pressure } \\
\quad(\mathrm{mm} \mathrm{Hg})\end{array}$ & $5.5 \pm 2.9$ & $5.9 \pm 3.0$ & .50 \\
$\begin{array}{l}\text { Pulmonary artery } \\
\quad \text { pressure (mm Hg) }\end{array}$ & $12.5 \pm 5.1$ & $12.9 \pm 3.5$ & .70 \\
$\begin{array}{l}\text { Ventricular end-diastolic } \\
\text { pressure (mm Hg) }\end{array}$ & $6.7 \pm 2.8$ & $6.7 \pm 3.2$ & .93 \\
$\begin{array}{l}\text { Pulmonary resistance } \\
\quad\left(\text { dyn } \times \mathrm{s}^{-5} \times \mathrm{cm}^{-5}\right)\end{array}$ & $1.4 \pm 0.8$ & $1.7 \pm .9$ & .14 \\
$\begin{array}{l}\text { Hemoglobin }(\mathrm{g} / \mathrm{dL}) \\
\text { Hematocrit }(\%)\end{array}$ & $19.1 \pm 2.5$ & $18.7 \pm 2.9$ & .42 \\
\hline
\end{tabular}

For RA-RV anastomoses, either the Bjoerk ${ }^{17}$ modification $(\mathrm{n}=60)$ with a polytetrafluoroethylene* tunnel or an allograft $(n=10)$ was used. For RA-PA connection, either a direct right atrial to pulmonary artery anastomosis $(\mathrm{n}=$ $26)^{18}$ or allografts $(\mathrm{n}=14)$ or a lateral tunnel constructed with autologous atrial tissue $(n=52)$ was used. Between patients with Fontan failure and survivors, no significant difference for preoperative mean pulmonary artery pressure, mean indexed pulmonary artery resistance, mean right atrial pressure, mean ventricular end-diastolic pressure, and mean hematocrit and hemoglobin values was found (Table 1). Preoperatively, $154(95.1 \%)$ patients were in sinus rhythm, and 4 patients showed atrial fibrillation or intermittent tachycardias that could be controlled by medical therapy. In 2 patients pacemakers for treatment of bradyarrhythmia were implanted. The mean age at the time of the Fontan operation was significantly $(P=.04)$ different, being $7.8 \pm$ 5.9 (SD) years (median, 6.1 years) for patients with $\operatorname{TrA}$ and $9.7 \pm 5.6$ years (median, 7.8 years) for patients with CCMs. The mean Fontan circulation time was significantly $(P=$ $.002)$ longer for patients with $\operatorname{TrA}(13.5 \pm 4.8$ years; median, 13.9 years) compared with that for patients with CCMs (10.9 \pm 5.3 years; median, 12.4 years). The KaplanMeier estimate of overall freedom from Fontan failure was $89.0 \% \pm 2.4 \%, 83.0 \% \pm 3.8 \%, 77.0 \% \pm 3.5 \%$, and $59.0 \%$ $\pm 7.7 \%$ at $5,10,15$, and 20 years' follow-up (Figure 1). The Kaplan-Meier estimate of freedom from Fontan failure at 15 years was significantly $(P=.007, \log$-rank test) higher for patients with $\operatorname{TrA}(83.0 \% \pm 4.0 \%)$ compared with that for patients with CCMs $(70.8 \% \pm 5.5 \%)$. In $17(11 \%)$ patients conversion of the modified Fontan pathway to total cavopulmonary connection was performed during follow-up.

*Gore-Tex, registered trademark of W. L. Gore \& Associates, Inc, Newark, Del.

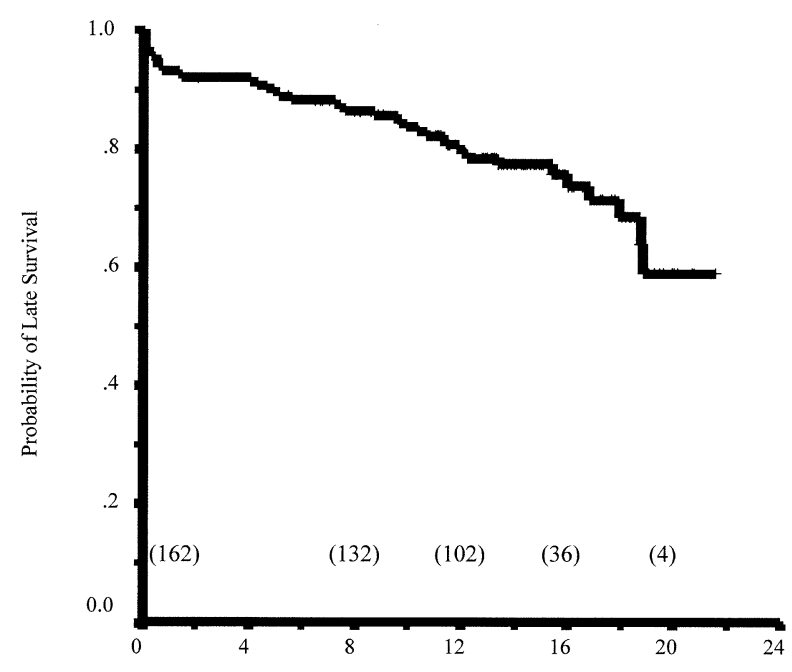

Time since Fontan Procedure (Years)

Figure 1. Kaplan-Meier estimates of the probability of late survival with a Fontan circulation. Time zero is $\mathbf{3 0}$ days after the Fontan operation. Numbers of patients at risk are shown in parentheses.

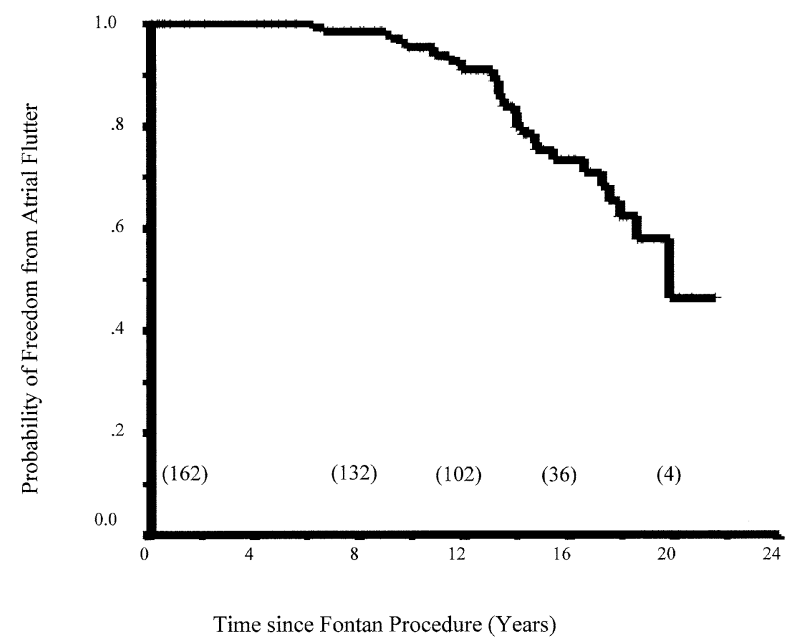

Figure 2. Kaplan-Meier estimates of the probability of freedom from atrial flutter. Time zero is $\mathbf{3 0}$ days after the Fontan operation. Numbers of patients at risk are shown in parentheses.

\section{Surgical Procedures}

The mean duration of cardiopulmonary bypass time was significantly $(P<.001)$ shorter for patients with $\operatorname{TrA}(90.0$ \pm 22.0 minutes; range, $30-153$ minutes) compared with that for patients with CCMs $(122.0 \pm 37.0$ minutes; range, 52-210 minutes). In addition, the crossclamp time was significantly $(P=.005)$ shorter in patients with $\operatorname{TrA}(50.0 \pm$ 17.0 minutes; range, 4-79 minutes) than in patients with CCMs (62.0 \pm 29.0 minutes; range, 2-132 minutes). How- 
TABLE 2. Predictors of late failure and IART after the modified Fontan operation

\begin{tabular}{|c|c|c|c|c|}
\hline \multirow[b]{2}{*}{ Variable } & \multicolumn{2}{|c|}{ Univariable } & \multicolumn{2}{|c|}{ Multivariable } \\
\hline & $P$ value & Risk ratio* & $95 \% \mathrm{CI}$ & $P$ value \\
\hline \multicolumn{5}{|l|}{ Late failure } \\
\hline Age & .20 & & & \\
\hline Diagnosis & .007 & 2.3 & $1.2-4.5$ & .009 \\
\hline SV-morphology & .06 & & & \\
\hline Heterotaxy syndrome & .87 & & & \\
\hline Pulmonary artery band & .54 & & & \\
\hline Surgical modification & .33 & & & \\
\hline Reoperation & .10 & & & \\
\hline Primary Fontan & .20 & & & \\
\hline Allograft & .42 & & & \\
\hline \multicolumn{5}{|l|}{ IART } \\
\hline Age & .27 & & & \\
\hline Diagnosis & .30 & & & \\
\hline SV-morphology & .97 & & & \\
\hline Pulmonary artery band & .59 & & & \\
\hline Surgical modification & .05 & & & \\
\hline Reoperation & .21 & & & \\
\hline Primary Fontan & .46 & & & \\
\hline Allograft & .77 & & & \\
\hline Follow-up & $<.001$ & .008 & $.00-.26$ & .006 \\
\hline Fontan failure & .17 & & & \\
\hline
\end{tabular}

$\mathrm{Cl}$, Confidence interval; $\mathrm{Age}$, age at Fontan operation ( $<4$ years); Diagnosis, tricuspid atresia versus complex congenital malformation; SV-morphology, left or right single-ventricle morphology; Pulmonary artery band, pulmonary artery banding versus systemic to pulmonary artery shunt; Surgical modification, right atrial to pulmonary versus right atrial to right ventricle connection; Primary Fontan, without pre-Fontan palliation; Allograft, right atrium to pulmonary artery or right ventricle connection with an allograft; Follow-up, Fontan circulation time less than 15 years.

*Risk ratio represents the hazards ratio from the Cox proportional-hazards model.

ever, univariable and multivariable analysis identified the type of diagnosis (TrA vs CCM) as the only variable significantly associated with late Fontan failure (Table 2).

\section{Patients With IART}

A total of $30(18.5 \%)$ long-term Fontan survivors had a history of intermittent or chronic IART (Figure 2), which was treated through the electrophysiologic approach. The Fontan circulation time was significantly $(P=.003, \log -$ rank test) longer in patients who underwent electrophysiologic testing (14.9 \pm 3.1 years; median, 14.5 years) compared with in patients without testing $(11.8 \pm 5.4$ years; median, 12.7 years). Univariable testing exhibited that the prevalence of atrial flutter was significantly $(P=.05$, logrank test) different for the 2 types of Fontan pathways: 18 (20\%) of 92 patients with the RA-PA Fontan modification experienced IARTs versus $12(17 \%)$ of 70 patients with RA-RV connections (Figure 3). Yet multivariable Cox regression analysis failed to associate the type of Fontan pathway as an independent risk factor for the development

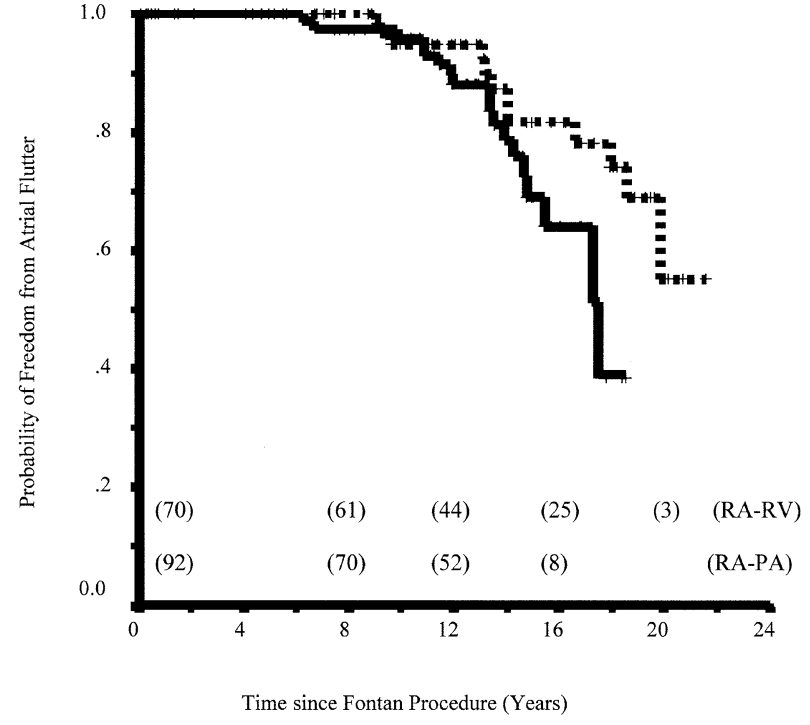

Figure 3. Kaplan-Meier estimates of the probability of freedom from atrial flutter as a function of the type of Fontan operation: $R A-P A$, right atrial to pulmonary artery (solid line), $R A-R V$, right atrial to right ventricle (dashed line). Time zero is $\mathbf{3 0}$ days after the Fontan operation. Numbers of patients at risk are shown in parentheses. The type of Fontan operation was significantly $(P=$ .05 , log-rank test) different for patients in whom atrial flutter developed.

of IART (Table 2). The variable of reoperation (among them 17 patients with conversion of the Fontan pathway to total cavopulmonary connection) did not reach significance either for late failure or for incidence of tachycardia. In 3 patients, before electrophysiologic ablation therapy, conversion with intracardiac baffling was performed. At that time, patients did not have re-entrant tachycardia but rather had other signs of Fontan disease. In one patient targeted excision of a left atrial tachycardia triggering focus in combination with conversion to cavopulmonary connection was performed. At follow-up, this patient presented with sinus rhythm. The age at the time of the Fontan operation in patients in whom tachycardias developed $(8.1 \pm 5.5$ years; median, 6.5 years) was not significantly different than that of those without tachycardias $(8.7 \pm 5.9$ years; median, 6.8 years).

During the first electrophysiologic approach, ablation of the tachycardia was not possible in $5(17 \%)$ patients (Table $3)$. The mean number of radiofrequency applications was 29 \pm 15 (range, 14-59). Fluoroscopic time was $39 \pm 13$ minutes (range, 20-65 minutes). In patients with initially successful ablation procedures, a total of 46 different sustained atrial tachycardias were induced (a mean of 1.8 tachycardias per patient). The critical isthmus was localized at 2 major sites: (1) the region between the tricuspid annulus and the inferior vena cava (22 patients) and (2) the area 
TABLE 3. Patient characteristics

\begin{tabular}{|c|c|c|c|c|c|c|c|}
\hline \multirow[b]{2}{*}{ IDNR } & \multirow[b]{2}{*}{ Diagnosis } & \multirow[b]{2}{*}{ Age at Fontan (y) } & \multirow{2}{*}{$\begin{array}{c}\text { Fontan circulation } \\
\text { (y) }\end{array}$} & \multirow[b]{2}{*}{ Fontan operation } & \multirow{2}{*}{$\begin{array}{c}\text { EPM } \\
\text { follow-up } \\
\text { (y) }\end{array}$} & \multicolumn{2}{|r|}{ Follow-up } \\
\hline & & & & & & Rhythm & Treatment \\
\hline 337 & TrA & 0.5 & 13.6 & RA-RV conduit & 0.5 & SR & $\beta$-blocker \\
\hline 167 & $\operatorname{TrA}$ & 10.7 & 14.3 & RA-RV conduit & 0.2 & SR & Amiodarone \\
\hline 153 & $\operatorname{TrA}$ & 2.5 & 11.6 & RA-RV conduit & 2.4 & SR & Amiodarone \\
\hline 149 & TrA & 4.8 & 14.0 & RA-RV conduit & 5.0 & SR & $\beta$-blocker \\
\hline 134 & $\operatorname{TrA}$ & 5.8 & 12.2 & RA-RV conduit & 3.6 & SR & \\
\hline 112 & TrA & 1.4 & 14.1 & RA-RV conduit & 0.7 & SR & $\beta$-blocker \\
\hline 106 & $\operatorname{TrA}$ & 2.1 & 15.8 & RA-RV conduit & 2.7 & SR & $\beta$-blocker \\
\hline 104 & $\operatorname{TrA}$ & 15.9 & 17.7 & RA-RV conduit & 1.1 & SR & Amiodarone \\
\hline 103 & $\operatorname{TrA}$ & 2.9 & 18.8 & RA-RV conduit & 0.9 & SR & \\
\hline 094 & $\operatorname{TrA}$ & 7.3 & 20.7 & RA-RV conduit & 0.9 & SR & $\beta$-blocker \\
\hline 092 & $\operatorname{TrA}$ & 1.4 & 19.1 & RA-RV conduit & 0.5 & SR & Amiodarone \\
\hline 076 & $\operatorname{TrA}$ & 3.5 & 18.3 & RA-RV conduit & 4.3 & IART & Propafenone \\
\hline 087 & $\operatorname{TrA}$ & 4.7 & 19.9 & RA-PA allograft & 2.7 & SR & Amiodarone \\
\hline 228 & $\operatorname{TrA}$ & 15.3 & 14.8 & RA-PA allograft & 0.9 & IART & $\beta$-blocker \\
\hline 068 & $\operatorname{TrA}$ & 7.5 & 16.7 & RA-PA allograft & 3.4 & IART & $\beta$-blocker \\
\hline 064 & $\operatorname{TrA}$ & 10.7 & 15.9 & RA-PA allograft & 2.4 & PM & $\beta$-blocker \\
\hline 070 & TrA & 6.1 & 16.6 & RA-PA direct & 1.2 & SR & \\
\hline 151 & CCM & 7.6 & 7.2 & RA-PA direct & 1.0 & IART & \\
\hline 119 & CCM & 18.0 & 13.6 & RA-PA direct & 2.8 & IART & Amiodarone \\
\hline 038 & CCM & 8.0 & 18.1 & RA-PA conduit & 0.6 & SR & Targeted excision \\
\hline 176 & CCM & 13.0 & 9.7 & Lateral tunnel & 3.0 & SR & $\beta$-blocker \\
\hline 057 & TrA & 6.0 & 15.1 & Lateral tunnel & 0.4 & SR & $\beta$-blocker \\
\hline 169 & CCM & 6.9 & 11.2 & Lateral tunnel & 1.3 & SR & $\beta$-blocker \\
\hline 135 & CCM & 4.5 & 12.2 & Lateral tunnel & 1.4 & SR & \\
\hline 123 & CCM & 14.5 & 13.2 & Lateral tunnel & 2.8 & SR & $\beta$-blocker \\
\hline 121 & CCM & 6.1 & 12.9 & Lateral tunnel & 1.0 & SR & $\beta$-blocker \\
\hline 033 & CCM & 16.8 & 17.2 & Lateral tunnel & 3.5 & IART & $\beta$-blocker \\
\hline 025 & CCM & 16.2 & 14.3 & Lateral tunnel & 1.0 & SR & \\
\hline 021 & CCM & 1.8 & 15.1 & Lateral tunnel & 0.3 & PM & $\beta$-blocker \\
\hline 019 & CCM & 19.2 & 14.1 & Lateral tunnel & 2.3 & PM & \\
\hline
\end{tabular}

IDNR, Identification number; $\operatorname{Tr} A$, tricuspid atresia; $C C M$, complex congenital malformation; $R A-R V$ conduit, right atrial to right ventricular connection with Dacron roof (Fontan-Bjoerk); $R A-P A$ allograft, right atrial to pulmonary artery connection with allograft; $R A-P A$ direct, right atrial to pulmonary artery connection without foreign material; $R A-P A$ conduit, right atrial to pulmonary artery connection with dacron tube; lateral tunnel, lateral tunnel from right atrial to pulmonary artery with atrial tissue; $E P M$, electrophysiologic mapping; $S R$, sinus rhythm; $I A R T$, intra-atrial re-entry tachycardia, $P M$, pacemaker.

between the inferior border of a lateral atriotomy and the inferior vena cava ( 9 patients). Also, the area between the superior border to the superior vena cava and the area between the septal patch to the inferior vena cava was frequently involved. In 3 patients tachycardia manifested as focal tachycardia. Two patients underwent repeat electrophysiologic testing, and tachycardias could finally be ablated. The other patients are awaiting surgical therapy. The mean follow-up duration in patients with successful ablation was 1.7 years (95\% confidence interval, 1.2-2.3 years). The Kaplan-Meier estimates for freedom from tachycardia in patients with initially successful ablation was $81 \% \pm 10 \%$ at 3 years' follow-up (Figure 4).

\section{Discussion}

The present study demonstrates that in patients with modified Fontan procedures, the incidence of IART significantly contributes to late morbidity. At 20 years, Kaplan-Meier analysis estimated $46 \%$ of the patients to be free from IART. Multivariable Cox regression testing revealed the duration of Fontan circulation as the sole risk factor associated with IART. By using recently introduced electrophysiologic techniques for electroanatomic atrial mapping, identification of the pathologic pathways and ablation therapy can achieve sinus rhythm in a high percentage of the patients. Surgical intervention should therefore be reserved for those patients with failed electrophysiologic therapy.

\section{Risk Factors for Late Fontan Failure}

The surgical procedures used in this Fontan series resulted in a functional status that was found to be comparable with data reported in the literature. ${ }^{19}$ Four large series ${ }^{1,2,8,20}$ have provided important information about late outcome after the modified Fontan operation. Yet comparison of outcome measures between institutions is not possible without fully 


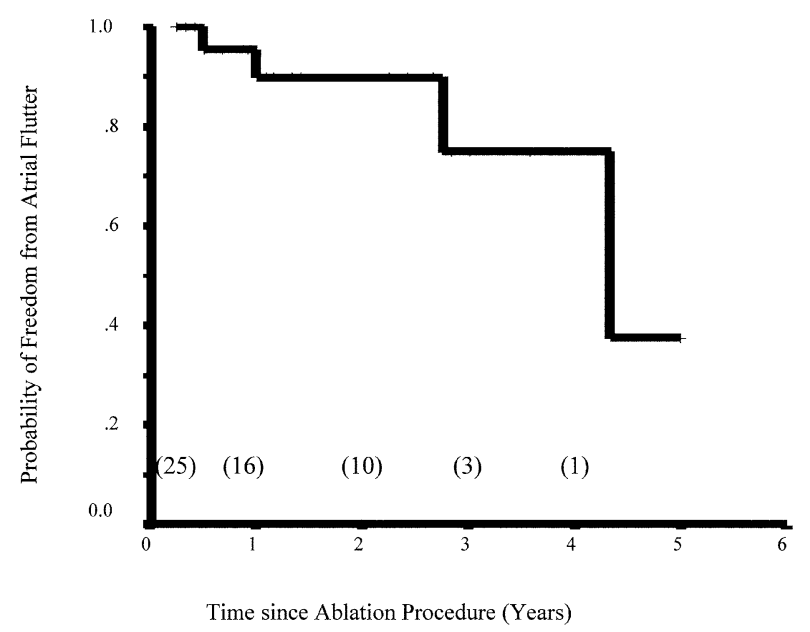

Figure 4. Kaplan-Meier estimates of the probability of freedom from atrial flutter as a function of time after the electrophysiologic ablation procedure in patients with immediate successful termination of the re-entrant tachycardia. Time zero indicates after the intervention. Numbers of patients at risk are shown in parentheses.

accounting for patient selection, surgical modifications, time of operation, interventional catheter techniques, and postoperative management. Nevertheless, Kaplan-Meier estimates of late Fontan failure in our series (eg, at 15 years being $77.0 \% \pm 3.5 \%$ ) are comparable with those published in the above-mentioned series. Multivariate Cox proportional hazard testing showed the diagnosis of CCM as significantly associated with Fontan failure. These data indicate that patient-related but not procedure-related variables determine the outcome in patients undergoing the Fontan operation during late follow-up.

\section{Risk Factors for IART}

The development of tachycardia during the life of a patient who has undergone the Fontan operation has been a matter of concern since the introduction of the Fontan procedure in 1971. ${ }^{21}$ In our Fontan population the development of tachycardia was clearly a time-dependent process (Figure 2). To overcome the uncertainty of the clinical significance of IART after the Fontan operation, we defined the time until the first IART treatment, determined by means of radiofrequency ablation, as an outcome parameter. The KaplanMeier estimated freedom from tachycardia is similar to values published from other series. ${ }^{5,6}$ In general, patients with an RA-RV anastomosis had a more simple underlying cardiac malformation compared with the patients with RA-PA anastomoses (Figure 3). This might explain why patients with RA-RV connections had a significantly (during univariable analysis) lesser incidence of tachycardia. Yet in the multivariable Cox proportional-hazard model, this difference was lost, and duration of follow-up remained the only significant variable for the development of tachycardia (Table 2). Summarizing the data from this and 2 recent studies ${ }^{5,6}$ doing an overview of 995 patients undergoing the Fontan operation, the duration of the follow-up interval, ${ }^{5}$ prior palliation with atrial septectomy, ${ }^{5}$ and atrioventricular valve replacement ${ }^{6}$ remain independent risk factors for the development of atrial tachycardia after the modified Fontan operation.

\section{Management for IART}

In patients undergoing the Fontan operation, the critical isthmus for the re-entrant circuit in atrial flutter was located between the tricuspid annulus, the coronary sinus, and the Eustachian ridge adjacent to the inferior vena cava. ${ }^{22}$ This region was also involved in the majority of our patients. In addition, further zones of slow conduction that define a critical isthmus in which radiofrequency ablation is likely to be successful have been identified and were also targeted: between the atriotomy and (1) the tricuspid annulus or the (2) superior or (3) inferior vena cava or (4) between the tricuspid annulus and the Fontan conduit. We performed an electroanatomic mapping technique for identification of the critical tachycardia zone, of which a detailed description has been recently published. ${ }^{23}$ This technique offers at least 3 advantages for mapping and guiding ablation of IARTs after the Fontan operation: (1) acquisition of multiple and simultaneous recordings; (2) software-assisted activation maps that rapidly identify zones of split potentials and slow conduction that can be further analyzed with an entrainment technique as possible targets for radiofrequency ablation; and (3) multiple and stable rows of electrodes representing a reliable tool to verify the completeness of the ablation lines.

Early and high recurrence rates of tachycardia after electrophysiologic ablation therapy have been reported in a small series of patients undergoing the Fontan operation. ${ }^{10}$ Therefore right atrial Cox maze procedure, pacemaker insertion, and conversion to total cavopulmonary connection was recommended as first-choice therapy in these patients. ${ }^{11-13}$ However, comparison of outcome measures between institutions is not possible for the same reasons mentioned above. Furthermore, innovation of the electrophysiologic technique (eg, introduction of bidirectional pacing to assess lesion continuity and better software) and gaining experience might influence early and late success. ${ }^{16,23}$ By using this technique, $80 \%$ freedom from IART at 3 years' follow-up or reduction of tachycardia frequency could be achieved. In our experience patients with tachycardia do not frequently have a failing Fontan circulation, which would facilitate indication for conversion to cavopulmonary connection. Therefore our concept is that surgical intervention should be reserved for those patients with 
failed electrophysiologic ablation or IARTs with failing Fontan circulation.

\section{Limitations of the Study}

The validity of our study is clearly limited by its retrospective nature and evaluation of data in a nonconsecutive patient group. Although long-term follow-up information was available in a high percentage of the patients, the incidence of IART is most likely underestimated because of the transient nature of some arrhythmias and the limited availability of serial electrocardiographic and Holter studies. Interpretation of the results is also difficult because there is a lack of an unoperated or conventionally palliated patient population as a control group.

Since 1995, we have changed our institutional policy and abandoned the modified Fontan operations described in this series. Recent data from patients with total cavopulmonary anastomose ${ }^{14}$ indicate that the lateral tunnel approach with prosthetic material and early correction of cyanosis considerably reduces the incidence of atrial arrhythmia compared with that of the patient group presented in this article. Thus this article might serve as a basis for future studies, clarifying the long-term outcome and treatment approach for IART in patients with the older Fontan modifications.

\section{Conclusions}

In this retrospective study we have shown that late survival after the Fontan operation was significantly determined by the patients' underlying congenital malformations. The long-term survival was estimated to be higher in patients with TrA compared with that in patients with CCM. IART develops over time after the Fontan operation, regardless of the type of underlying morphology. By using 3-dimensional atrial electroanatomic activation mapping, rapid and comprehensive therapy of re-entrant atrial tachyarrhythmias in patients undergoing the Fontan operation is achieved. Surgical intervention should be reserved for those patients who do not respond to interventional therapy.

\section{References}

1. Fontan F, Kirklin JW, Fernandes G. Outcome after a perfect Fontan operation. Circulation. 1990;81:1520-36.

2. Driscoll DJ, Offord KP, Feldt DF, Schaff H, Puga FJ, Danielson G. Five- to fifteen-year follow-up after Fontan operation. Circulation. 1992;85:469-96.

3. Mertens L, Hagler AJ, Sauer U, Somerville J, Gewillig M. Proteinlosing enteropathy after the Fontan operation: an international multicenter study. J Thorac Cardiovasc Surg. 1998;115:1063-73.

4. Balling G, Vogt M, Kaemmerer H, Eicken A, Meisner H, Hess J. Intracardiac thrombus formation after the Fontan operation. $J$ Thorac Cardiovasc Surg. 2000;119:745-52.

5. Fishberger SB, Wernovsky G, Gentles TL, Gauvreau K, Burnett J, Mayer JE, et al. Factors that influence the development of atrial flutter after the Fontan operation. J Thorac Cardiovasc Surg. 1997;113:80-6.

6. Durongpisitkul K, Porter CJ, Cetta F, Offord KP, Slezak JM, Puga FJ, et al. Predictors of early- and late-onset supraventricular tachyarrhythmias after Fontan operation. Circulation. 1998;98:1099-107.
7. Gentles TL, Gauvreau K, Mayer JE Jr, Fishberger SB, Burnett J, Colan $\mathrm{SD}$, et al. Functional outcome after the Fontan operation: factors influencing late morbidity. J Thorac Cardiovasc Surg. 1997;114:392403.

8. Gentles TL, Mayer JE Jr, Gauvreau K, Newburger JW, Lock JE, Kupferschmid JP, et al. Fontan operation in five hundred consecutive patients: factors influencing early and late outcome. $J$ Thorac Cardiovasc Surg. 1997;114:376-91.

9. Triedmann JK, Bergau DM, Saul JP, Epstein MR, Walsh EP. Efficacy of radiofrequency ablation for control of intraatrial reentrant tachycardia in patients with congenital heart disease. J Am Coll Cardiol. 1997;30:1032-38.

10. Betts TR, Roberts PR, Allen SA, Salmon AP, Keeton BR, Haw MP, et al. Electrophysiological mapping and ablation of intra-atrial reentry tachycardia after Fontan surgery with the use of a noncontact mapping system. Circulation. 2000;102:419-25.

11. Deal BJ, Mavroudis C, Backer CL, Buck SH, Jonsrude C. Comparison of anatomic isthmus block with the modified right atrial maze procedure for late atrial tachycardia in Fontan patients. Circulation. 2002; 106:575-9.

12. Mavroudis C, Backer CL, Deal BJ, Johnsrude CL. Fontan conversion to cavopulmonary connection and arrhythmia circuit cryoablation. J Thorac Cardiovasc Surg. 1998;115:547-56.

13. Mavroudis C, Backer CL, Deal BJ, Johnsrude CL. Total cavopulmonary conversion and maze procedure for patients with failure of the Fontan operation. J Thorac Cardiovasc Surg. 2001;122:863-71.

14. Stamm S, Friehs I, Mayer JE, Zurakowski D, Triedmann JK, Moran AM, et al. Long-term results of the lateral tunnel Fontan operation. J Thorac Cardiovasc Surg. 2001;121:28-41.

15. Schmitt C, Zrenner B, Schneider M, Karch MR, Ndrepepa G, Deisenhofer I, et al. Clinical experience with a novel multielectrode basket catheter in right atrial tachycardias. Circulation. 1999;99:2414-22.

16. Zrenner B, Ndrepepa G, Schneider M, Karch MR, Hofmann F, Schoemig A, et al. Computer assisted animation of atrial tachycardias recorded with a 64-electrode basket catheter. J Am Coll Cardiol. 1999;34:2051-60.

17. Bjoerk V, Olin CL, Bjarke BB, Thoren CA. Right atrial-right ventricular anastomosis for correction of tricuspid atresia. J Thorac Cardiovasc Surg. 1979;77:452-8.

18. Kreutzer G, Galindez E, Bono H, de Palma C, Laura JP. An operation for the correction of tricuspid atresia. $J$ Thorac Cardiovasc Surg. 1973;66:105-11.

19. Weipert J, Koch W, Haehnel JC, Meisner H. Exercise capacity and mid-term survival after in patients with tricuspid atresia and complex congenital cardiac malformation modified Fontan-operation. Eur J Cardiothorac Surg. 1997;12:574-80.

20. Knott-Craig CJ, Danielson GK, Schaff H, Puga F, Weaver A, Driscoll D. The modified Fontan operation. An analysis of risk factors for early postoperative death or takedown in 702 consecutive patients from one institution. J Thorac Cardiovasc Surg. 1995;109(6):1237-43.

21. Fontan F, Baudet E. Surgical repair of tricuspid atresia. Thorax. 1971;26:240-8.

22. Chan DP, van Hare GF, Mackall JA, Carlson MD, Waldo AL. Importance of atrial flutter isthmus in postoperative intra-atrial reentrant tachycardia. Circulation. 2000;102:1283-9.

23. Zrenner B, Ndrepepa G, Schneider M, Karch MR, Brodherr-Heberlin $\mathrm{S}$, Kaemmerer $\mathrm{H}$, et al. Mapping and ablation of atrial arrhythmias after surgical correction of congenital heart disease guided by a $64-$ electrode basket catheter. Am J Cardiol. 2001;88:573-8.

\section{Discussion}

Dr Constantine Mavroudis (Chicago, Ill). Dr Weipert and associates have presented their experience with 162 patients undergoing the Fontan operation with varying types of venoatrial pulmonary artery connections. Congratulations on a very nice presentation. It was clear, succinct, and easy to follow.

Dr Weipert and associates divided their patients into 2 groups, namely the TrA group and the complex group. The incidence of atrial tachycardia over time was documented, and they also 
showed the benefits of transcatheter ablation in controlling atrial arrhythmias in some 25 patients. Their results are better than most in the literature, but nevertheless, they have a $50 \%$ recurrence rate over a 5-year period. This article was nicely presented and serves as an important benchmark because of the significant follow-up, which includes approximately 2000 patient-years.

Our experience at Children's Memorial Hospital in Chicago has centered on those patients who had Fontan failure on the basis of atrial arrhythmias, pathway obstructions, and valvular dysfunction. In your article you thought that it was unlikely that arrhythmias would be the sole cause of Fontan failure. We have a differing opinion in that we have seen a number of patients who have had atrial arrhythmias over long periods of time who have ventricular dysfunction and have regained their ventricular function after the maze procedure. Perhaps you could comment on this issue.

I have several other questions. I see from the article that you excluded patients with hypoplastic left heart syndrome. Is it because you had few patients like this, or have you excluded others with other more complex anatomy, and if you did, can you tell us why?

Also, did you see a difference in the transcatheter ablation success rate between the patients with TrA and your complex congenital patients? The reason I ask this is because the patients with $\operatorname{TrA}$ tend to have thicker atrial walls and might not be treatable by means of energy-giving techniques because of the difficulty in creating transmural lesions. You might want to give us some thoughts on that.

And another thing, I did not see in your long follow-up any patients who had atrial fibrillation. Did any of your patients have atrial fibrillation? We contend that atrial fibrillation is the natural course after atrial re-entrant tachycardia for a significant number of these patients; that is to say, the first arrhythmia is atrial re-entrant tachycardia followed in time with atrial fibrillation. If you did have patients like that, did you take these patients to the catheterization laboratory and try to perform a left- and right-sided maze procedure to convert them or did you operate on them?

We do not have a problem with performing transcatheter ablation for our sets of patients. However, we find that a number of these patients have pathway obstructions and anatomic problems as well, and therefore we usually go to surgical intervention with these patients.

I look forward to your comments, and I also look forward to your transcatheter techniques getting better, where these patients hopefully will not have to have an operation that is as large as this one.

Dr Weipert. Thank you very much, Dr Mavroudis. I skipped the problem of conversion operation to total cavopulmonary connection in these patients, but we did 17 conversions in patients with the full symptoms of Fontan disease, such as together with fibrillation, flutter, and protein-losing enteropathy, and there was a mortality rate of about $25 \%$. Therefore we are reluctant to go ahead and do the operation in patients who have flutter, which I could present here.
Fibrillation, when it is disturbing the patient, might be also an indication to try catheter ablation, but when it is with a normal heart rate, it is not.

Patients with hypoplastic left heart syndrome were excluded, and they were not amenable for this type of Fontan operation. And we could not see a difference at present between the patients with TrA and the other patient group with regard to the success rate or ablation rate. The patient numbers are too small, and the numbers of failures are too small also. Atrial fibrillation alone is not an indication to convert the Fontan tunnel to a total cavapulmonary anastomosis.

Dr Marcus Haw (Southampton, United Kingdom). I come from a center from which Dr Batts published his results with ablation, and therefore we congratulate you with your fantastic results for transcatheter intervention.

We followed very much Dr Mavroudis' line in treating these patients, and we have almost invariably found with the traditional type of atriopulmonary connection that patients have a good deal of effort intolerance, as well as the intermittent flutter, and I wonder if you have any sort of outcome data in terms of your patients' functional status after a successful ablation?

Dr Weipert. The follow-up is short, and we do not have functional data at present. Patients were satisfied with their clinical condition when atrial flutter could be abolished or arrhythmia frequency decreased. But we do not have objective methods where we can say it is really an advantage for this patient.

Dr Haw. Thank you.

Dr Thomas L. Spray (Philadelphia, $\mathrm{Pa}$ ). How many of these patients in late follow-up ended up with a pacemaker, and how many are still receiving antiarrhythmia medications?

Dr Weipert. Three patients ended up with a pacemaker, and 3 of them are taking amiodarone.

Dr Spray. And are they all receiving $\beta$-blockers or only a selected portion?

Dr Weipert. Most of the patients are receiving $\beta$-blockers.

Dr Carlos Troconis (Caracas, Venezuela). Are those arrhythmias surgically related, or were they related to dilatation of the right atrium?

The reason for my question is because in the past 5 years, we have operated on 3 patients older than 18 years with extracardiac conduit, and all of them had normal sinus rhythm at follow-up. On the other hand, we have 20 cases (2-4 years of age at operation) over 10 years' follow-up of extracardiac conduit, and we have not seen any surgically related arrhythmias at all.

Dr Weipert. The lateral tunnel Fontan operation might be very promising for the future.

There was a recent article from the Boston group: at 10 years, $90 \%$ of the patients with a lateral tunnel were free from new supraventricular tachycardias. The lateral tunnel approach probably is the best solution for the univentricular heart at present.

In the patient with a failing Fontan operation, when there are surgically amenable lesions, we go ahead and make a conversion, but in these patients this was not the case. 